\title{
A First-Hand Account of Title IV-E Child Welfare Initiatives in Social Work Education and Practice
}

\begin{abstract}
Alberta J. Ellett
Abstract: This article describes the personal experiences and insights of a child welfare practitioner and professor derived from 20 years of involvement in IV-E agency/university partnerships. The author describes perspectives from her work in IV-E programs in multiple contexts (federal, state, and local). Included are descriptions of important historical events and changes in IV-E programs that have served to facilitate or impede successful child welfare practices and the education of IV-E students. Emphasis is given to the importance of: (a) communicating the complexity of work in child welfare particularly by IV-E students; (b) the challenge of sustaining effective IV-E partnership programs; (c) designing and implementing sound IV-E program evaluation procedures; and (d) understanding the political and policy-driven contexts framing current $C W$ practices.
\end{abstract}

Keywords: Child welfare, IV-E partnerships, workforce professionalization

After 25 years of public child welfare practice as a caseworker (GA \& LA), supervisor (GA \& LA), state office foster care program manager, and IV-E agency/university partnership administrator (LA), I decided it was time to recruit, educate and prepare the next generation of child welfare employees. Of course becoming a higher education faculty member required a doctorate. I entered the Louisiana State University (LSU) social work Ph.D. program in 1996 which meant that I had to be focused to graduate before I began collecting Social Security. I made this career change in 2000 as an assistant professor where I continue as a professor at the University of Georgia (UGA), School of Social Work. My experiences in a variety of positions in public child welfare and experiences as a social work faculty member have provided me with multiple personal perspectives on current concepts, issues, and practices in CW.

This article traces the evolution of the Title IV-E funded social work education initiatives following the de-professionalization of child welfare (CW) through my firsthand experiences in child welfare practice, policy, education, and research over the past four decades. Social work educators have the responsibility to prepare IV-E graduates to be competent practitioners in their work with families which have multiple problems and needs, and to work with other child welfare employees in stressful and difficult environments. The national IV-E historical context for social work educators is described followed by personal experiences in Louisiana as the state office administrator of the IVE university/agency partnerships, as the UGA Director of the IV-E Child Welfare Education Program, and several of my national level activities. It concludes with needs and some optimism for the future of a long and grand-intermingling of SW education and CW practice.

Alberta J. Ellett, Ph.D., is an Associate Professor in the University of Georgia School of Social Work in Athens, GA.

Copyright @ 2014 Advances in Social Work Vol. 15 No. 1 (Spring 2014), 63-79 


\section{National Policy, Legal, and Practice Context}

The U.S. Children's Bureau (CB) was established in 1912 at the same time that social work (SW) education was emerging in universities. Because there were few child welfare programs available to address child maltreatment, foster care and adoption issues, the CB and SW education began to collaboratively address these needs (Thomas, 2012). The IVE social work education initiative evolved from long standing support from the CB that a social work education provided the knowledge and skills necessary to intervene in family matters as sensitive and serious as child welfare. The Social Security Act of 1935 provided the first federal child welfare program at the state level. The CB provided funding for states to send their CW employees for a SW degree with over 55\% of all public CW employees acquiring at least one year of graduate SW education in 1955; however this figure dropped to 30\% by 1961 (Coll, 1995). By the late 1970s, only 28\% of public child welfare employees had social work degrees (Coll, 1995; Lieberman, Hornby, \& Russell, 1988). Perhaps as a result of the IV-E social work educational programs, this number has improved to 39.5\% (Barth, Lloyd, Christ, Chapman, \& Dickinson, 2008). Historically, the CB provided a number of funding streams for child welfare employee professional development in BSW and MSW education through Titles IV-A (the '60s), XX (the '70s), and IV-E (1980-present) (Zlotnik, 2003). All of these were considered inadequate due to limitations within the legislation and related appropriation levels to professionalize CW practitioners with social work credentials.

Many factors contributed to the de-professionalization of the child welfare workforce (Ellett \& Leighninger, 2007). For example, the 1962 service amendments to the SSA combined the Aid to Families with Dependent Children (AFDC) and child welfare employees resulting in the $\mathrm{CB}$ losing several major functions and most of its professional identity (Leiby, 1978). While the number of AFDC families grew, the caseloads for child welfare services were simultaneously increasing more rapidly from public awareness of child abuse and neglect (Costin, Karger, \& Stoesz, 1996). Following the passage of the Child Abuse and Neglect Prevention and Treatment Act (CAPTA) in 1974, the number of children reported as maltreated increased exponentially. During the 1970s, the numbers of children in foster care swelled to over 500,000, many of whom were growing up in state custody (Costin et al., 1996).

States responded to public criticism, high caseloads, underfunding, and inadequate numbers of social workers for child welfare positions by dropping the social work degree requirement, with some states dropping a college degree altogether, to fill positions paying lower wages (Karger, 1982). Recognizing that they lacked the time and resources to adequately train new $\mathrm{CW}$ employees, states responded administratively by compartmentalizing CW work to individual programs, i.e., intake, child protective services, foster care, and adoption narrowly training employees to do tasks in their respective programs (Steib \& Blome, 2003, 2004).

The social work profession was also developing competing areas of practice such as mental health, school social work, and community organization which siphoned SW students from CW practice (Kadushin, 1987). During the 1970s, some Schools of Social Work dramatically expanded their programs by funding faculty through Title XX. When 
Title XX was block granted and funding evaporated for SW education, some schools nearly collapsed and many simply dropped child welfare content from their curricula. With Title XX funding eliminated for SW education, what historically had been a close and collaborative working relationship between schools of SW and state CW agencies with the shared goal to professionalize CW grew distant (Costin et al., 1996).

\section{IV-E Legislation}

In an effort to remedy the problem of too many children in foster care growing up in state custody, the Adoption Assistance and Child Welfare Act of 1980 (Title IV-E of the SSA) was enacted. This legislation aimed to lower the number of children and shorten their time in foster care through (a) reasonable efforts to prevent removal and to reunify families, (b) case plans, and (c) permanency via time frames to qualify for federal funds. Title IV-E (IV-E) of the Social Security Act provides federal authorization and funding for U.S. public foster care and adoption programs. Foster children's IV-E eligibility applied only to children at the time of their removal whose parents would have been eligible for AFDC. The IV-E legislation was passed under the Carter Administration, but it came up for appropriation under the Reagan Administration which prohibited issuance of regulations. The Title IV-E law as written was long, technical, and included a brief, obscure clause funding training. States and universities were slow to discover and widely implement IV-E funded training until the 1990s. The legislative intent was to provide $75 \%$ federal funding for short and long term (BSW/MSW) training for CW employees and potential employees with states contributing the remaining 25\%. However, the Reagan administration imposed restrictions significantly reducing the intended amount of federal funding for training to the percent of IV-E eligible children multiplied by .75 . California and Pennsylvania (county administered programs) and Kentucky were among the earliest states to implement IV-E initiatives with multiple universities participating in statewide consortia.

\section{Child Welfare Practice Context}

When I began working in public child welfare as a caseworker in 1970 it was still a prestigious and respected area of social work practice and was viewed positively by the general public. This seems remarkable given my BS degree in microbiology; I knew immediately that I needed a MSW degree to successfully assess and engage families to acquire healthier means to parent along with addressing issues of substance abuse, mental illness, domestic violence, and poverty. I worked with clients from intake to closure, i.e. child protective services (CPS), foster care, reunification, relative guardianship, and adoption and learned from my mistakes to improve outcomes for children and their families.

I graduated with my MSW in 1974 to become the first child welfare supervisor in a NE Georgia county. Little did I understand that I entered a CW practice context that was in a rapid era of change due to growing caseloads, woeful underfunding, and public resentment towards welfare (AFDC, food stamps, Medicaid). At the same time, the first federal abuse and neglect reporting legislation had been enacted (CAPTA). There was no 
child protective services protocol to follow, leaving me to read and interpret the law with no additional resources.

\section{Experiences as an Agency IV-E University Partnership Administrator}

\section{Program Development and Implementation}

The Louisiana State University (LSU) Dean of the School of Social Work, Dr. James Midgley, and the Louisiana Assistant Secretary for the Department of Social Services, Brenda Kelley, discussed starting a IV-E child welfare/social work education partnership in 1993. I was selected as the CW state agency IV-E administrator for this partnership. My involvement began with a meeting with Dean Midgley and Professor Marian Fatout, assigned to direct LSU's IV-E child welfare education program.

At the same time, Dr. Carol Williams, who headed the U.S. Children's Bureau under the Clinton Administration, held a national IV-E conference in 1993 to encourage public agencies and universities to develop partnerships to provide social work education for CW employees and potential employees through stipends. Dr. Fatout and I attended this conference and began our seven year working relationship during which we developed and implemented a pilot model at LSU before expanding to other Louisiana universities. As I recall, Dr. Kathy Briar-Lawson (now dean of the SSW at SUNY-Albany) was one of the keynote speakers who inspired many attendees with her energetic enthusiasm for IVE funded SW education to improve client outcomes. Not only was the IV-E conference informative, it was exciting to become part of a national movement to inject SW back into CW practice. As I knew all too well, someone could work a lifetime in CW and never receive permission to attend a national conference. It was particularly gratifying that LSU would insist that I also attend the Council on Social Work Education (CSWE) and the Intensive Home-Based Family Preservation conferences to learn how other states had developed and implemented their models of partnership programs with IV-E funding. Additionally, we traveled to Arkansas to meet with the state office IV-E Administrator and Trainer as well as with Kenneth Millar, Social Work Dean, University of Arkansas at Little Rock, who had maximized IV-E dollars providing all pre-service and in-service CW agency training.

Soon thereafter, a regional meeting in Dallas with the U.S. Region VI Administration for Children and Families (ACF) was held for state IV-E partnership administrators to explain allowed and disallowed IV-E expenses universities could include in their IV-E contract proposals and invoices for which state administrators would be responsible. The ACF Program Manager, Joe Woodard, championed IV-E partnerships, provided fascinating overheads of what appeared to be integrally entangled wires that turned out to represent the very complicated IV-E and child welfare funding mechanism. Considerable IV-E organizational complexity (federal, regional, state, university) was evident from the beginning of this new thrust to enhance professionalization and the quality of CW services. The IV-E rate varied annually and differing university federal cost share rates compounded the complexity of participating university partnership budgets. 
During the 1990s in Louisiana, the MSW was the preferred degree for workers and a requirement for Department of Social Service (DSS) CW supervisors and most administrators. DSS set aside IV-E funds for employees to obtain the MSW degree to further increase the numbers of DSS child welfare employees holding social work degrees. Thus, Louisiana DSS reserved the IV-E university partnership stipends for potential DSS employees in MSW and BSW programs. Dr. Fatout announced the IV-E stipend program and we developed objective stipend student selection criteria for the first cohort of IV-E MSW LSU students using a point system that included grades. The university partnership IV-E program included curriculum with CW content, a public CW agency internship, and a DSS work obligation. At the end of the first semester, two of the six students withdrew from or were counseled out the program because they were afraid of the clients, didn't want to make home visits, were found by agency personnel to be illsuited for CW, etc. Fortunately the Louisiana partnership was initially pilot tested at LSU to identify and correct unexpected consequences rather than implement problems statewide with all universities. The following year the IV-E education program was expanded to three additional universities with BSW programs. A written IV-E application asked open-ended questions eliciting motivation to work in $\mathrm{CW}, \mathrm{CW}$ knowledge, relevant SW experiences, CW values, and a writing sample. In addition to the application, faculty recommendations were used to invite students to an interview with faculty and local agency administrators who made joint student selections. These requirements represented an improved selection process that also included a IV-E program orientation for selected students and faculty prior to the fall semester. Two moreBSW/MSW programs joined the third year, and the last university was added the following year for a total of seven Louisiana IV-E participating universities.

\section{Some Personal Perspectives}

Over the seven years that I administered the program for the Louisiana child welfare agency, I experienced a few surprises: (a) a few students who experienced extreme child maltreatment could not separate their personal biases to work with parents; (b) criminal records checks and driving records yielded important information; (c) two universities had substantial central campus dysfunction related to students receiving their stipends in a timely manner; (d) CW content was not adequately addressed unless these were standalone courses; (f) agency employees were initially reluctant to take on the added responsibility to provide student supervision, but became enthusiastic supporters once graduates were hired; (g) the state Merit System didn't permit the hiring of BSW IV-E graduates because they lacked paid experience; (h) funds provided for field supervisors to attend a national CW conference encouraged others to become student supervisors; (i) IV-E BSW graduates who were allowed to delay employment to enter as IV-E MSW students were less likely to complete their CW work obligations; (j) IV-E graduates who left DSS employment were often hired by agencies that worked with CW clients; (k) nonIV-E students learned about CW from IV-E students; and (l) few faculty could assist in developing evaluation tools. When I was informed that BSW graduates could not be hired, I worked with our Human Resources Director and met with Merit System administrators to substitute IV-E student internships for the required one year of paid experience. 


\section{Program Evaluation}

With assistance from LSU Educational Research Professor, Chad Ellett, I developed a Solomon Four Group evaluation plan which became impossible to implement because it included comparison of the annual personnel evaluation of non-IV-E new hires with IV-E new hires. However, I developed a multiple choice CW knowledge exam because there was none that had demonstrated initial validity or reliability characteristics. LSU hired Kristin Gansle, Ph.D. as the evaluator for the seven participating schools. The Louisiana Examination of Child Welfare Information (LECWI) was administered to IV-E and nonIV-E BSW and MSW students at the beginning of the academic year and again at the end of the year (Gansle \& Ellett, 2002). In successive years, faculty at all participating universities were requested to submit10 questions for inclusion in the LECWI to expand the exam item bank and delete unreliable questions after item analyses were completed annually. Cronbach Alpha reliabilities were computed yearly which saw increases from 1994/95 (Alpha=.53) through 1998/99 (Alpha=.84).

IV-E BSW and MSW students' scores on the LECWI were significantly higher on both pre and post-test than non-IV-E students. Some 83\% of IV-E MSW and 33\% of BSW graduates were employed by DSS in child welfare positions. Of the IV-E graduates employed, $55 \%$ of MSWs and $84 \%$ of BSW remained employed at the time I resigned as the IV-E administrator in 2000 to join UGA School of Social Work faculty. The employee turnover rate of all new agency hires within the first three years of employment was 39\% (C. Ellett, 1995), so it appears that the IV-E grads had longer retention rates and were promoted within DSS. After I left as the IV-E partnership administrator, the program was terminated within a couple of years. It appears that state leadership and professional commitment to IV-E SW education were important to IV-E program sustainability.

\section{Faculty Experiences as PI and Director of a University IV-E Program}

Upon completing my doctorate in 2000 at LSU in Social Work with a minor in Industrial and Organizational Psychology, I had the good fortune to be hired as an Assistant Professor at the UGA, School of Social Work for my CW and IV-E expertise. The first IV-E program in Georgia was initiated by Dr. Jim Gaudin (UGA) in 1995 who shared his knowledge with four other universities. Thus, five social work schools had a loose affiliation with the Georgia Division of Family and Children Services (DFCS). They met periodically together with the agency administrator regarding their annual IV-E contract renewal. In Georgia, though the MSW and BSW were preferred degrees, only $20 \%$ of DFCS child welfare employees had social work degrees (Ellett, Ellett, \& Rugutt, 2003). The UGA School of Social Work initially reserved IV-E stipends for DFCS employees, which was not the case at all participating universities. Gaudin developed a course on social work with abusing and neglecting families, held four half-day seminars each semester, and students completed practicum internships in an alternate DFCS child welfare program to meet CSWE accreditation standards. In 2000 there were $10 \mathrm{MSW}$ stipends and the total UGA contract was \$158,300. Gaudin retired in December, 2000 and I became the Director and PI of successive IV-E contracts from 2001-2011. Gaudin 
also had a 426 Children's Bureau Demonstration stipend grant for BSW students that I was also asked to direct.

\section{IV-E Expansion}

As PI and Director of the IV-E program in 2001, I raised funding to $\$ 723,695$ and increased the number of student stipends to include students as well as DFCS employees in the MSW program. Two UGA doctoral students with extensive CW experience were funded by the IV-E contract to (a) teach BSW child welfare and MSW practice courses and (b) serve as IV-E faculty liaisons. Because it is imperative for IV-E students to also graduate with foster care and adoption knowledge and skills, I developed a second required CW course on social work with foster and adoptive families. To increase CW professional commitment, students could attend a state CW conference and DFCS Field Supervisors of IV-E students were funded to attend a state or national conference. A stipend selection committee was developed that included DFCS administrators, the two doctoral students, and me to select students with a genuine interest in CW as a career. The IV-E contract included summer salary and travel money for the PI to present, attend and network at CSWE, SSWR, and the bi-annual National Child Abuse and Neglect conference sponsored by the U.S. Children's Bureau.

There were several fortuitous situations that developed soon after I joined the UGA faculty. Because the 2000 employee turnover rate of Georgia DFCS child welfare employees was 44\%, the Annie E. Casey Foundation and DFCS agreed to fund an employee turnover study. I recommended that it would be far more important to do an employee retention study rather than one that studied those who left DFCS. In the end, I was PI for this sole-source contract to UGA and completed the 2003 Georgia DFCS Child Welfare Employee Retention and Turnover Study which identified personal and organizational factors related to both staying and leaving. From this study, we collected empirical evidence that IV-E graduates had stronger intentions to remain employed in child welfare than other graduates (Ellett et al., 2003). This study also examined relationships between employees' intentions to remain employed in CW and a variety of organizational and personal characteristics such as work morale, job satisfaction, organizational culture, self-efficacy beliefs, and human caring (Ellett et al., 2003). Of the many significant findings from this large statewide study $(\mathrm{N}=1423)$, one in particular stands out. The variable showing the strongest positive relationship to intentions to remain employed in CW was Professional Commitment ( $\mathrm{r}=.67 ; \mathrm{p}<.0001)$, a subscale of a larger measure of human caring.

At about the same time, a faculty colleague, Dr. Geraldine Jackson-White, who had previously worked in DFCS, chose to return to the DFCS state office as the Director of Professional Development. She provided much needed leadership to expand IV-E partnerships by adding three new university social work programs and two private universities for a total of 10 participating universities. All-day university/agency consortium meetings were held monthly to develop fairly uniform IV-E funded competency-based CW education programs including: (a) two specific CW courses in the BSW and MSW programs; (b) DFCS internships including specific delineated CW tasks;

(c) DFCS work obligation; (d) an orientation each fall; (e) stipend selection committees 
that included both DFCS administrators and faculty; and (f) a UGA administered, multisite, standardized evaluation with all ten universities.

In 2000, in the DFCS 12-county Region V, there were only a handful of CW employees with a SW degree. To meet CSWE requirements to provide the minimum onehour per week of field supervision, one of the doctoral students provided this supervision until there was an adequate number of IV-E MSW graduates employed for two years in DFCS. The regional and county directors not only hired all IV-E graduates wishing to work in the region, they also secured state funding for two years to hire selected IV-E MSW students as part-time employees to carry five cases in their last semester of their MSW program. Region V had the largest proportion of BSW and MSW employees in the state with $40 \%$ by 2009 . The UGA School of Social Work has benefitted by having adequate numbers of DFCS employees with two years post graduate experience willing to supervise internship students. Nearly all DFCS child welfare employees participating in the IV-E program were promoted while in the MSW program. Many received additional promotions following graduation and have risen to county and regional directors and state office positions.

The DFCS asked me to develop a multi-method, research-based Employee Selection Protocol (ESP). This protocol was designed for use as a new set of assessment procedures comprising minimally essential, work-related knowledge, skills, abilities and values (Ellett, Ellett, Ellis, \& Lerner, 2009; Ellett, Ellett, Westbrook, \& Learner, 2006). While originally designed for use with DFCS job applicants, the ESP was used by the 10 university IV-E partnerships to improve student selection procedures. One goal of the ESP as used in these IV-E partnerships was to increase retention rates of IV-E graduates. This new approach to select IV-E students was implemented with considerable success until IV-E funding was suspended in 2011.

In 2005, a class-action settlement involving GA DFCS's two largest counties included a provision that supervisors needed to have two years CW experience and a SW degree (Kenny A. vs. Sonny Perdue Consent Decree). In response to this situation, DFCS included funding for UGA to double the number of MSW students admitted into the MSW part-time program located in Greater Atlanta and enabled more of its employees to become eligible to supervise. We made several presentations in DFCS country offices to recruit employees to fill this added MSW cohort. UGA had the largest IV-E budget (over two million dollars) including match and 64 stipend students, half of whom were DFCS employees.

At UGA, I have had a continuous flow of IV-E graduates entering our doctoral program following their agency work commitment. These IV-E MSW alumni who obtain their doctorate degrees help retain CW content and practice in SW curriculum in addition to expanding CW research.

\section{IV-E Suspension}

Following the Great Recession beginning in 2007, Georgia DFCS experienced substantial budget cuts over 5 years and four years of employee furloughs, was no longer able to help universities with IV-E match funding. It became incumbent upon universities 
to generate all IV-E matching funds. Concomitantly tuition was rising and universities experienced about $20 \%$ in state funding cuts that shrank the number of stipend students in IV-E social work programs. To maximize IV-E funds to sustain child welfare programs, DFCS altered its method to draw down IV-E funds which universities were instructed to use. In the summer of 2011, Region IV Administration for Children and Families (ACF) disallowed some methods DFCS used to claim federal funds including the IV-E universities education programs. The ACF wanted DFCS to contribute some state match dollars to enable continuation of the 10 IV-E partnerships; however after enduring extreme budget cuts, DFCS didn't have the needed matching funds to continue the partnership. The DHS Commissioner and DFCS Director called an urgent meeting of the ten partnership universities July 13, 2011 and announced the suspension of the IV-E program effective August, 2011. This was devastating news for universities as IV-E proposals had been submitted months earlier, and IV-E personnel and students had been selected with fall classes to begin in less than a month. There were a few UGA IV-E students who had received stipend support in the prior years who had DFCS work obligations upon their graduation in 2012. These remaining IV-E BSW and MSW graduates helped DFCS fill vacancies. DFCS regional and county directors reported that the quality of new hires had declined following the IV-E suspension. At the request of Georgia DFCS, schools of social work submitted contract proposals in March, 2014 to resume the IV-E program fall 2014; however, in April, 2014, universities were notified that resumption will be delayed until January, 2015 due to concerns about ACF financing approval.

\section{The Unexpected}

In complex, policy-based initiatives like IV-E there are many unexpected events that serve to impede or facilitate program implementation. This has certainly been the case with IV-E in Georgia. Unexpected impediments to the Georgia's 16 year IV-E partnership experience included (a) a revolving door of politically appointed DHHS Commissioners and DFCS Directors lacking child welfare experience and social work education; (b) difficulty getting IV-E grads to complete evaluation surveys and tracking the length of their employment; (c) six-month contract approval process resulting in universities running their programs sometimes as long as three months before final contracts were officially signed; (d) after the Great Recession DFCS experienced a substantial loss of its state funding which was magnified with the loss of federal dollars resulting in universities putting up all the match money most years; (e) change in IV-E funding claims led to the sudden and unexpected suspension of all IV-E partnerships July 13, 2011; (f) most faculty and staff with CW experience on IV-E contracts were in temporary status and many social work programs dropped CW courses; and (g) many non-IV-E SW faculty dissuaded students from entering DFCS CW employment. The section that follows provides a description of personal experiences and perspectives of national IV-E efforts. 


\section{Some National Experiences and Perspectives on IV-E}

\section{IV-E Programs Wax and Wane}

A primary influence on my IV-E perspectives has been shaped by attending and participating in national professional organizations and meetings. Among these was the conference entitled the Child Welfare Training Partnerships for the $21^{\text {st }}$ Century Workforce Conference, a Special Meeting of the U.S. Children's Bureau. This national conference, held in 2000, had wide professional endorsement of groups such as the Council for Social Work Education (CSWE); the National Association of Social Workers; the National Association of Public Child Welfare Administrators; and the Child Welfare League of America. In this national CB meeting there was obvious excitement for expanding IV-E partnerships. This meeting helped further spread the development of IV-E university/state agency partnerships from 68 in 1996 (Zlotnik \& Cornelius, 2000) to 144 in 2004 (Barbee, Antle, Sullivan, Dryden, \& Henry, 2012). At the same time, there was growing recognition from the Social Work National Association of Deans and Directors (NADD) of the importance of IV-E participation for SW programs to prepare graduates for careers in CW. The NADD formed an active CW task force and began a small, annual invitational conference around IV-E and workforce research from 20022005. Jean Quam, Dean, University of Minnesota, hosted the first invitational conference in 2002 and I followed with the second 2003 NADD workforce conference at UGA. Kristi Nelson, Dean, Portland State University, held the third conference in 2004. The University of North Carolina postponed hosting the fourth conference in 2005 as the CB was holding a national workforce conference the same summer.

Sustaining increases in the number of university/state agency partnerships has been difficult. Joan Zlotnik found in the latest IV-E partnership study that $70 \%$ of respondents indicated that their funding had stayed the same or declined, and five schools reported termination of their IV-E program (Zlotnik, 2012). The number reported in this study likely did not include all 10 university partnerships suspended in Georgia.

\section{CSWE Pre-Conference IV-E Partnership}

Attending the Council on Social Work Education (CSWE) Annual Program Meeting (APM) for the first time in 1996, I was pleased to attend many child welfare sessions including IV-E. However, I was shocked there was no special interest child welfare track given the long history between SW education and CW, so I initiated one. The CSWE criteria to establish a proposed track included a written request, ten abstracts submitted to the proposed CW track with five accepted through the blind review process. In 1997 at a plenary session on IV-E Partnerships, I circulated a petition supporting the need for a CW Track. Forty nine attendees signed the petition that I submitted along with a letter proposing a CW Track in CSWE. From these 49 supporters plus 30 people who had attended Joan Zlotnik's roundtable, we encouraged individuals to submit abstracts to the proposed CW track for the 1998 conference. Ten abstracts were submitted and five were accepted through a blind review process, thus meeting CSWE's Track criteria. Following the first CW Tract business meeting in 1998, the new Track grew quickly in 2000 to four pre-conference meetings including three specifically addressing IV-E partnership issues 
plus a business meeting prior to opening of the annual program meeting. It was from these meetings that a IV-E email distribution list was established by Sherrill Clark from the IV-E California Social Work Consortium. Crystal Collins-Camargo set up a IV-E Partnership website while at the University of Kentucky, and Monit Cheung (University of Houston) organized and still maintains a matrix reporting specifics of each IV-E university program. The CW Track was the largest CSWE Track measured by the number of abstracts submitted for 2-3 years $(\mathrm{N}=75-80)$ and the second largest for several years. I was elected and Chaired the CW Track from 1998-2013. To foster sustainability of Tracks, CSWE instituted a system of three-year Co-Chairs followed by three years as Chair in 2011; Crystal Collins-Camargo was the first elected Co-chair and Helen Calhane was elected Co-chair in 2013. There have been many participants who volunteered in the development, evolution, sustainability, and success of the CSWE CW Track which has been held out as a model for other CSWE Tracks. Clearly the national IV-E effort has increased BSW and MSW programs' interest and participation in the professionalization of the CW workforce.

An unobtrusive indicator of waning federal financial support for IV-E university and state agency partnership programs was a dramatic drop in CSWE CW Track abstract submissions in 2013. Submissions dropped from a high of 82 to 50 and attendance at preconference all day sessions dropped over the years from 175 to 81 .

My experiences in attending and participating in IV-E topical meetings sponsored by professional SW organizations including CSWE and the Society for Social Work and Research (SSWR) through the years have been mostly positive. My observations suggest that: (a) sessions with child welfare and workforce focus have increased and been well

attended; (b) participants have provided valuable insights, research, and expressed valid concerns about IV-E; (c) there is general consensus that IV-E partnerships prepare graduates for CW practice; (d) IV-E graduates have longer CW agency retention rates than other new hires; (e) partnership programs enhance communications between agency personnel and university faculty targeting the improvement of professional preparation and practice; and (f) a few IV-E programs (Kentucky and Texas) have been able to link better client outcomes of IV-E graduates than non-IV-E employees.

\section{IV-E Education/Agency Hurdles}

From the CSWE CW Track partnership pre-conference meetings and discussion on the IV-E Partnership listserv (I agreed to host at the UGA SSW after Clark at CASWEC could no longer do so), evidence grew that each of the ten Regional offices of the Administration on Children and Families (ACF) interpreted the IV-E legislation and allowable expenses differently. This created angst for states and universities that continues to this day. Also, as individuals in ACF regional offices left, their replacements arrived at alternate decisions on allowable spending not only for their respective regions, but between states within the same region. Over the past 20 years, states that had long standing IV-E agency/education partnerships were terminated or suspended (e.g., Florida, Georgia, Hawaii, Illinois, Kansas, Maine, Michigan, New Jersey, South Carolina, Tennessee, Vermont, and Virginia). Some ACF decisions were compounded after the CB developed regulations limiting topics for which IV-E funds could be utilized in short and 
long term training. These decisions have served to sanitize or purify SW curricula qualifying for this critical source of funding. Oddly, the CB does not have oversight of the ACF regional offices that approve or disallow IV-E budgets and expenditures. This structure has contributed to confusion and disruption for university and state agency partnerships.

Following the great recession, state child welfare agencies including Georgia have experienced budget cuts further limiting their available state matching funds for Title IVE federal aid. Many state legislatures have significantly cut funding to higher education resulting in colleges and universities steadily increasing student tuition and fees which in turn limits the number of students that social work programs can fund through IV-E stipends. The loss of temporary faculty and professional staff working in IV-E university partnerships has resulted in the loss of expertise and diminished CW in Georgia schools and departments of SW. Other university partnerships also report the declining rate of IVE eligible children (tied to 1996 AFDC eligibility) and rising tuition and fees have lowered the number of IV-E stipends. States' percentages of children eligible for IV-E funds have drastically decreased, for example, from approximately $75 \%$ in 1980 to half or less than that in 2014. Limiting federal funds to support state foster care and adoption programs has also impacted the rate of funding for short and long-term training.

Social work educators have experienced many successes with their IV-E programs, but they have been stymied in efforts to systematically evaluate results. For example, in Louisiana, completing evaluation tasks was a requirement for all universities. Completing the same knowledge exam was essential to implementation of a quality program evaluation design that included a non-IV-E new hires comparison with IV-E graduates. The state agency disallowed these comparisons. Georgia's evaluation plan was approved to use the comparison groups of new IV-E and non-IV-E workers. However, the response rate of both new hire groups was too low to draw meaningful statistical conclusions. In both states, access to employment data was not permitted. Clearly, efforts to accurately assess and evaluate retention and promotion of IV-E graduates have been problematic. A national group of IV-E researchers has for many years tried to link client outcomes with IV-E graduates. However, high turnover (multiple workers per case) has confounded these efforts. Evaluation data are important in assessing program quality, outcomes, and sustainability. Policy makers remain interested in these evaluation concerns. Patrick Leung, University of Houston, has provided considerable leadership in IV-E evaluation efforts.

\section{Optimism for Child Welfare Agency and Social Work Education IV-E Partnerships}

The Children's Bureau has renewed its recognition of the importance of a stable and competent CW workforce in recent years. In 2003, the Children's Bureau recognized the importance of SW educated employees in retention and quality of service delivery through eight retention grants and doctoral child welfare research grants. In 2003, I was Principal Investigator on a CB research grant that supported four CW doctoral students' dissertation studies on CW and workforce factors related to employee retention. In 2008 
the CB funded the National Child Welfare Workforce Institute (NCWWI) supporting: (a) 12 university/agency partnerships; (b) training through a Leadership Academy of Supervision (LAS); and (c) a Leadership Academy of Middle Managers (LAMM). The NCWWI funding was renewed for another five years in 2013: (a) supporting 11 new university/agency partnerships; (b) developing a Leadership Academy for SS Deans/Directors and State CW Directors; and (c) continuing the LAS and LAMM.

Randi Walters, a CB Program Specialist and IV-E graduate, has presented in the CSWE pre-conference CW Track IV-E Partnership meetings beginning in 2011. Such meetings have presented opportunities for IV-E faculty to share successes and needs of the IV-E program. For example, IV-E graduates have longer retention rates than other new hires and promotion of IV-E graduates builds leadership capacity within state CW organizations. It was my hope in originating the CW Track that it would institutionalize CW within the CSWE, SSWR, and schools of social work curricula, especially if Congress were to defund IV-E for training in higher education.

On another positive note, Alvin Sallee, University of Houston, began the annual Title IV-E National Roundtable Conference in 2011 to maintain the momentum for Schools of SW and state agency collaborations. This roundtable conference is an important opportunity for IV-E partners to identify and discus issues and concerns about elements of developing, implementing and sustaining programs.

During the 2003 NADD-sponsored small invitational conference, it became clear that more CW journals were needed to disseminate and accommodate the growth in CW research. Following this conference, Dean Katharine Briar-Lawson, SUNY-Albany approached Dean Marvin Feit, Norfolk State, about initiating a new CW journal through Haworth Press. In 2004, I accepted an appointment as co-editor of the new Journal of Public Child Welfare (JPCW). Following my work to establish an Editorial Board of national CW experts, call for papers, editorial work etc. the first volume was published and disseminated in 2007. Since 2008 the JPCW has been published by Routledge Taylor and Francis Groups and since 2011, I have been Editor-in-Chief. To honor and celebrate the CB centennial, Norma Harris (University of Utah) and I were Co-Editors of the JPCW double special issue One-Hundred Years of the U.S. Children's Bureau Professionalizing and Improving Child Welfare. The CB, through its contract with Information Gateway covered the cost of doubling the issue pages and printing 600 additional copies. The CB wrote the first article on the CB history and the last article on the CB's vision for the future of CW. This special issue addressed both the vital role of IV-E partnership programs play in the workforce and included four other articles specific to IV-E partnerships. The JPCW has also published a number of other articles on Title IV-E programs. While the NADD small annual invitational IV-E and workforce conference has not resumed, there is interest among NADD members to resume a CW IV-E task group.

As previously mentioned, I had the good fortune to work with the Georgia DFCS in 2006-2007 to develop an Employee Selection Protocol (ESP) which was, and will again, be utilized in the selection of IV-E stipend students interested in a CW career in all ten participating universities (Ellett et al., 2009; Ellett et al., 2006). The ESP has been 
presented at the Child Welfare Recruitment and Retention Summit in Denver, CO, 2008, the Children's Bureau Child Welfare Evaluation Summit, Washington, DC 2009, the National Conference on Child Abuse and Neglect (2012 \& 2014), and the CSWE and the SSWR annual conferences.

\section{Building on IV-E Experiences to Professionalize Child Welfare}

The vast majority of my experiences with the Title IV-E as a state administrator (1993), director of the UGA program from 2000, and at the national level since 1998 were positive until the suspension of Georgia's program in 2011. Of course, there have been many minor impediments to the success of my work in IV-E. Probably the greatest impediment I and others have encountered for the continued success CW and SW education has been confusing policy, inconsistent funding decisions for IV-E university/agency partnership programs, and the organizational structure in which IV-E is situated. Navigating this field of impediments is not easily done. For example, the CB recognizes the importance of IV-E in developing a professional CW workforce. However, the position of the CB within the ACF organization structure administratively cuts off the $\mathrm{CB}$ from supervising regional ACF personnel whom approve or disapprove state IV-E fiscal claims. My IV-E experiences over the years show that university CW partnership programs have been in need of CB leadership and revised regulations since the 1990s. Such leadership could invigorate these programs across states. Federal and state CW funding has always been inadequate and IV-E funding is further diminished with eligibility tied to parents' income pegged to 1996 AFDC rates under welfare reform legislation. Given the political climate, it seems clear that there has been little appetite to advocate for introducing revised legislation for fear of further reductions in funding.

\section{Some Final Thoughts}

I have been involved in one role or another in IV-E for over two decades. My experiences in IV-E related activities have varied considerably over time. These experiences have provided me with a set of broad perspectives about core elements of this national effort to enhance the professionalization of the CW workforce and ultimately client outcomes. The text that follows provides a brief and closing summary of my perspectives about the importance of student selection, quality evaluation, university/agency commitments, and clearer legislation and policy funding for the IV-E initiative.

Because most CW employees leave within the first two years of employment (U.S. GAO, 2003) student applicants need extensive information about the IV-E education program and CW work to make more informed decisions about a career in CW. Many students are attracted to IV-E programs because of the availability of stipend support provided rather than a broad understanding of the complexities of work in CW. As well, those preparing and hiring CW employees (educators and agency personnel) need better information about applicants' CW knowledge, skills, abilities and values to select individuals committed to a career in child welfare. University and agency collaborative working relationships are important to the success of programs, increasing advocacy for $\mathrm{CW}$, and improved practice interventions. Providing quality supervision is an important 
element of work in CW, particularly for new employees. Graduates of IV-E programs often promote to supervisors, managers, administrators and even directors. Thus, IV-E programs become an important conduit to enhance leadership quality and professional organizational capacity. This situation, in light of the larger workforce issue of high CW turnover (Ellett et al., 2003) suggests a continuing need to improve the process of selecting students for IV-E programs and prospective employees as well. Currently, we do not place enough emphasis on the importance of selection of IV-E students and CW employees.

As has been noted above, designing and implementing quality program evaluation procedures, has been a major IV-E challenge. Too frequently, IV-E evaluations have been fraught with design flaws and/or implementation issues that interfere with quality evaluation, including the difficulties of data collection procedures. Participation in many IV-E evaluation efforts is voluntary, and much lower than desired. Sampling considerations aside, low participation rates in IV-E evaluations tax the fidelity and generalizability of evaluation findings. As well, the need to establish linkages between IV-E education efforts and client outcomes remains an elusive butterfly. This situation suggests greater acknowledgement and support from agency and university partners for CW agencies to track IV-E graduates' employment and IV-E and non-IV-E employees' participation in evaluations. Increased resource allocations, both human and technical, are essential for completing stronger IV-E evaluations. As well, there is a future need to design more comprehensive program evaluations. The IV-E evaluation literature is replete with single method (qualitative or quantitative) studies and small sample sizes. Larger and more comprehensive evaluation studies are needed given the complexities of preparing CW professionals.

Because the quality of CW services and presumably client outcomes can only be as good as the knowledge and skill level of CW employees, revised legislation and policy is needed to clarify and adequately fund short and long term training for all CW programs. It is clear to me from my experiences that large-scale efforts such as IV-E in CW will stand or fall depending upon political support and accompanying policy. For example, needed supports for IV-E short and long-term training include: (a) clear legislative language to standardize IV-E programmatic efforts; (b) sufficient state and federal funding; (c) standardized and interpretable policies and regulations; (d) enhanced understanding between CW agencies and SW faculty; (e) clarifying the relationship between the $\mathrm{CB}$ and ACF regarding oversight of funding for IV-E partnerships; (f) clarifying and providing resources to improve the role of partnership evaluation; and (g) identifying a set of experienced and well-respected strategic champions to advocate for IV-E partnerships with policy makers and professional meetings of organizations such as NADD, NPCWA, CSWE, SSWR, NASW, CWLA. Given the availability of these supports, monitoring the sustainability of key IV-E program components and outcomes are key concerns. Policy makers are likely to be more supportive of IV-E partnerships that identify and document sustainability of outcomes as an important programmatic thrust, than those that do not. The suggestions provided above are those that this writer considers priorities. Those with different experiences and perspectives might well expand this list. 


\section{References}

Adoption Assistance and Child Welfare Act of 1980 (P.L 96-272).

Barbee, A. P., Antle, B. F., Sullivan, D. J., Dryden, A. A. A., \& Henry, K. (2012). Twenty-five years of the Children's Bureau investment in social work education. Journal of Public Child Welfare, 6, 376-389.

Barth, R. P., Lloyd, E. C., Christ, S. L., Chapman, M. V., \& Dickinson, N. S. (2008). Child welfare worker characteristics and job satisfaction: A national study. Social Work, 53, 199-209.

Coll, B. (1995). Safety net: Welfare and Social Security, 1929-1979. New Brunswick, NJ: Rutgers University Press

Costin, L., Karger, H., \& Stoesz, D. (1996). The politics of Child Abuse and Neglect in America. New York, NY: Oxford Press.

Ellett, A. J., Ellett, C. D., Ellis, J. I., \& Lerner, C. B. (2009). A Research-based child welfare employee selection protocol: Strengthening retention of the workforce. Child Welfare, 88, 49-68.

Ellett, A. J., Ellett, C. D., \& Rugutt, J. K. (2003). Final Report: A study of personal and organizational factors contributing to employee retention and turnover in child welfare in Georgia. Athens, GA: University of Georgia, School of Social Work.

Ellett, A. J., Ellett, C. D., Westbrook, T. M, \& Lerner, B. (2006). Toward the development of a research-based employee selection protocol: Implications for child welfare supervision, administration, and professional development. Professional Development: The International Journal of Continuing Social Work Education, 9(2/3), 111-120.

Ellett, A. J., \& Leighninger, L. (2007). What happened? An historical analysis of the deprofessionalization of child welfare with implications for policy and practice. Journal of Public Child Welfare, 1(1), 3-34.

Ellett, C. D. (1995). Louisiana Office of Community Services 1994-1995 statewide personnel needs study: Executive summary. Baton Rouge, LA: Office of Research and Economic Development, Louisiana State University.

Gansle, K., \& Ellett, A. J. (2002). Child welfare knowledge transmission, practitioner retention, and university-community impact: A study of Title IV-E child welfare training. Health and Social Policy, 15(3/4), 69-88.

Kadushin, A. (1987). Child welfare services. In A. Minahan (Ed.), Encyclopedia of Social Work (18th ed., Vol. I, pp. 265-275). Silver Spring, MD: NASW.

Karger, H. J. (1982). Reclassification: Is there a future in public welfare for the trained social worker? Social Work, 28(6), 427-433.

Kenny A. vs. Sonny Perdue Consent Decree. (2004). Retrieved from http://dfcs.dhs.georgia.gov/kenny-vs-sonny-perdue-consent-decree 
Leiby, J. (1978). A history of social welfare and social work in the United States. New York, NY: Columbia University Press.

Lieberman, A., Hornby, H., \& Russell, M. (1988). Analyzing the educational backgrounds and work experiences of child welfare personnel: A national study. Social Work, 33(6), 485-489.

Steib, S. D., \& Blome, W. W. (2003). Fatal error: The missing ingredient in child welfare reform: Part 1. Child Welfare, 86(6), 747-750.

Steib, S. D., \& Blome, W. W. (2004). Fatal error: The missing ingredient in child welfare reform: Part 2. Child Welfare, 87(1), 101-104.

Thomas, M. L. (2012). One hundred years of Children's Bureau support to the child welfare workforce. Journal of Public Child Welfare, 6, 357-375.

U. S. General Accounting Office. (2003). HHS could play a great role in helping child welfare agencies recruit and retain staff (GAO-03-357). Washington, DC: Author. Retrieved from http://www.gao.gov/assets/240/237373.pdf

Zlotnik, J. L., \& Cornelius, L., (2000). Preparing social work students for child welfare careers. The use of Title IV-E training funds in social work education. Journal of Baccalaureate Social Work, 5(2) 1-14.

Zlotnik, J. L. (2003). The use of Title IV-E training funds for social work education: An historical perspective. Journal of Human Behavior in the Social Environment, 7(1), 5-20.

Zlotnik, J. L. (2012). Laying the foundation for a stronger partnership under Title IV-E. In A. Lieberman \& K. Nelson (Eds.), Women and children first: The contributions of the Children's Bureau to social work education (pp. 89-111). Alexandria, VA: The Council on Social Work Education Press.

\section{Author note}

Address correspondence to: Alberta J. Ellett, Ph.D., Associate Professor, Tucker Hall 423, University of Georgia, Athens, GA 30602. Email: aellett@uga.edu

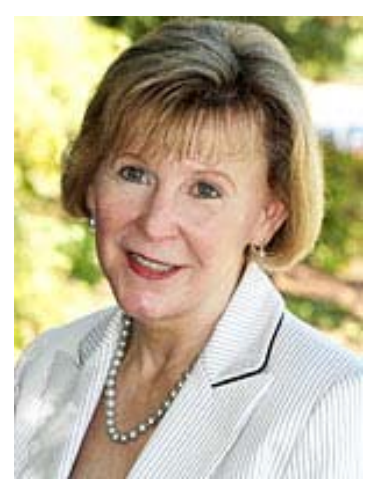

Alberta J. "Bert" Ellett, Ph.D., is an associate professor at the University of Georgia, School of Social Work joining the faculty in 2000. She received the 2010 Council of Social Work Education Distinguished Recent Contributions in Social Work Education Award. She is nationally known as a leader in several professional organizations through her contributions in promoting the continued professionalization of child welfare. Ellett was elected Secretary of the Society for Social Work and Research 2008-2011 and re-elected for 2011-2014. Her research interests and specializations center on developing child welfare organizations and strengthening their holding power in ways that retain and promote the development of competent child welfare staff. 